International Journal of Engineering \& Technology, $7(2.23)(2018) 1-3$
International Journal of Engineering \& Technology
WPC
Website www.sciencepubco.com/index.php/IJET
Research paper

\title{
Approach to analysis of technical -organizational system functioning on the base of semi-markov process theory
}

\author{
Aleksey Gavrilin ${ }^{1}$, Tatiana Gorbunova ${ }^{2,3}$ *, Marina Tumanova ${ }^{3}$ \& Oleg Ratnikov ${ }^{1}$ \\ ${ }^{1}$ Specialist, JSC «Radiozavod», Penza, Russia \\ ${ }^{2}$ PhD, Moscow State University of Civil Engineering (National Research University), Moscow, Russia \\ ${ }^{3}$ PhD, Moscow Polytechnic University, Moscow, Russia \\ *Corresponding author E-mail: tngorbunova@yandex.ru
}

\begin{abstract}
Relevance of the present task lays in optimization of control over complex systems considering probabilistic and temporal nature of their functioning. Allocated some generic States of the system's normal operation and consider destabilizing situations when the continued functioning of the element in the system becomes difficult, impossible. Including the status when it is necessary to conduct full diagnostic and restoring of the system with explicit damage which makes it impossible for the system to operate in the acceptable mode into the model is described in the work. The proposed solution to this task is based on the mathematical modelling. Considering the general case of nonexponential time of system residence in its own status, the proposed functioning model displays relations between system statuses and probable parameters of its functioning on the base of semi-Markov process theory. Because of this work the explanation of an adequate description of complex system functioning at probabilistic and temporal analysis was presented.
\end{abstract}

Keywords: automated control system; graph; semi-Markov process theory; special-purpose technical-organization system; technical element.

\section{Introduction}

System of human activity organization includes a considerable number of parameters. It is irrelative whether we regard construction sphere, manufacturing processes, education activities or solving military tasks. But the question of optimization of this activity is quite important for each sphere.

According to the theory of P.K. Anohin [1]: "Functional systems of living organisms are self-organizing, self-regulating dynamic organizations, all components of which interact and cooperate to achieve useful adaptive results for the system and organism as a whole". This theory turned out to be not only a universal explanation for processes in living organisms but also for processes in social environment and human society. It gave new possibilities for management activity optimization.

An approach for system functioning optimization is proposed according to which the considered system is presented as a behavioral graph with the following development of mathematical model on its base. It is proposed to build a mathematical model on the base of semi-Markov process theory.

\section{Task descriptions}

Different methods of mathematic modelling are widely used to increase validity of management decisions for manufacture subsystems of the industrial enterprise. Implementation of semiMarkov process theory can be regarded as one of the prospective approaches to building system models of that type; according to this theory value of probability to catch the sub-system in the desired status is considered as an efficiency index. The level of semiMarkov model's complexity is defined not only by the list of ac- countable factors but also by the corresponding level of complexity of the system itself, presence of diverse sub-systems, elements and interconnections. This was described in the works by Anohin in [2], Sudakov and Umriukhin in [3], Boyarinov and Mischenko in [4], Mhitaryan et al in [5], Gertsbakh in [6], Howard in [7].

Let us consider functioning of the element of a complex system. Let us mark out some universal statuses: preparing of the element for the task solving (purpose functioning) and the solutions itself, setting of the element for the solving of the next class of tasks. Also, we will regard destabilizing situations when the functioning of the element in the systems is hampered or impossible and the following period of restoring and setting. Including the status when it is necessary to conduct full diagnostic and restoring of the system with explicit damage which makes it impossible for the system to operate in the acceptable mode into the model is described by semi-Markovian model.

The phase portrait of the system element functioning process under study is specified by the status graph $G(P, Q)$ (fig. 1), by possible transitions, by matrix of independent functions of the element residence time distribution in the status $i$ before the transition to $j$ status, i.e. such functions that are possible if this transition from istatus was the only initial status in the moment of time $t=0$.

System element statuses according by Suprun and Vakal in [8] may be the following:

- $\quad S_{1}$ - element is being prepared for the purpose functioning;

- $\quad S_{2}$ - element is functioning on its purpose;

- $S_{3}$ - element is conducting transition to the setting for solving tasks of different class;

- $S_{4}$ - occurrence of the situation hampering continuation of task solving; 
- $S_{5}$ - occurrence of the situation that makes it impossible to continue task solving;

- $S_{6}$ - element restores functioning possibility.

Number of system element statuses equals 6 .

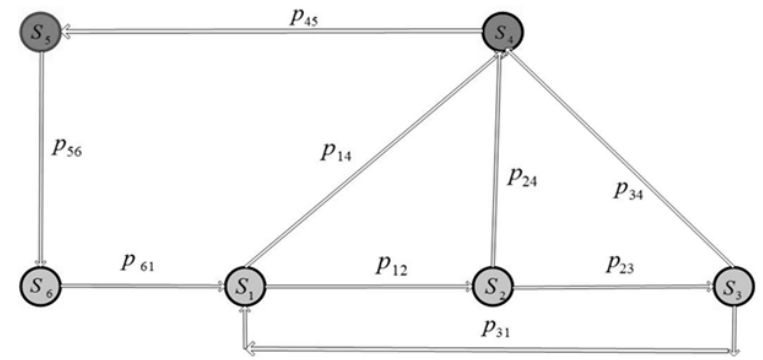

Fig. 1: Graph $\mathrm{G}(\mathrm{P}, \mathrm{Q})$ of system element functioning statuses.

Each of the element statuses is characterized by temporal parameters presented in table 1 .

Table 1: System element statuses and their characteristics

\begin{tabular}{|c|c|c|}
\hline \multirow{2}{*}{ Element status } & Element status characteristics \\
\cline { 2 - 3 } & Name & Sign \\
\hline $\begin{array}{c}\text { Element is being prepared } \\
\text { for the purpose functioning }\end{array}$ & $\begin{array}{c}\text { Mean time for } \\
\text { preparing for purpose } \\
\text { functioning }\end{array}$ & $t_{p}$ \\
\hline Functioning on the purpose & $\begin{array}{c}\text { Mean time of } \\
\text { functioning }\end{array}$ & $t_{f}$ \\
\hline $\begin{array}{c}\text { Element is conducting } \\
\text { transition to the setting for } \\
\text { solving tasks of different } \\
\text { class }\end{array}$ & $\begin{array}{c}\text { Mean time of } \\
\text { transition }\end{array}$ & $t_{t}$ \\
\hline $\begin{array}{c}\text { Occurrence of the situation } \\
\text { hampering continuation of } \\
\text { task solving }\end{array}$ & $\begin{array}{c}\text { Mean time of } \\
\text { hampering } \\
\text { occurrence }\end{array}$ & $t_{o c c}$ \\
\hline $\begin{array}{c}\text { Occurrence of the situation } \\
\text { that makes it impossible to } \\
\text { continue task solving }\end{array}$ & $\begin{array}{c}\text { Mean time of work } \\
\text { (functioning) } \\
\text { impossibility }\end{array}$ & $t_{i m p}$ \\
\hline Restoring period & Mean time of \\
restoring & $t_{r}$ \\
\hline
\end{tabular}

\section{Proposed method. Semi-Markov model}

It is necessary to define independent functions $Q_{i j}(t)$ when defining element statuses. Analytic form of independent distribution functions can be defined by statistical way on the base of putting forward and check of statistical hypotheses about types of distribution law by Kozlov and Stroikov in [9], Shubenin and Kozlov in [10].

As a result, the matrix of functions $Q_{i j}(t)$ is obtained:

$Q(t)=\left\|\begin{array}{|cccccc}0 & Q_{12}(t) & 0 & Q_{14}(t) & 0 & 0 \\ 0 & 0 & Q_{23}(t) & Q_{24}(t) & 0 & 0 \\ Q_{31}(t) & 0 & 0 & Q_{34}(t) & 0 & 0 \\ 0 & 0 & 0 & 0 & Q_{45}(t) & 0 \\ 0 & 0 & 0 & 0 & 0 & Q_{56}(t) \\ Q_{61}(t) & 0 & 0 & 0 & 0 & 0\end{array}\right\|$

Then if the adjacent status is present the probability of $p_{i j}(t)$ transition from $i$-status to $j$-status is calculated by formulae:

$p_{i j}(t)=\int_{0}^{t} \prod_{k \neq j}\left(1-Q_{i k}(t)\right) d Q_{i j}(t)$, where

- $\prod_{k \neq j}\left(1-Q_{i k}(t)\right) \quad$ is a probability of not leaving $i$-status during $t$ time in the line of $k \neq j$,

- $d Q_{i j}(t)$ is a probability of transition in the line of $j$ into neighborhood of $t$.

The matrix of transition probabilities for the presented graph will have the following form:

$$
p(t)=\left\|\begin{array}{|cccccc}
0 & p_{12}(t) & 0 & p_{14}(t) & 0 & 0 \\
0 & 0 & p_{23}(t) & p_{24}(t) & 0 & 0 \\
p_{31}(t) & 0 & 0 & p_{34}(t) & 0 & 0 \\
0 & 0 & 0 & 0 & p_{45}(t) & 0 \\
0 & 0 & 0 & 0 & 0 & p_{56}(t) \\
p_{61}(t) & 0 & 0 & 0 & 0 & 0
\end{array}\right\|
$$

Steady-state (stationary) value of transition probability $p_{i j}$ is obtained from the expression:

$p_{i j}=p_{i j}(t \rightarrow \propto)=$

$\lim _{i \rightarrow \infty} p_{i j}(t)=\int_{0}^{\propto} p_{i j}(t) d t=\int_{0}^{\propto} \prod_{k \neq j}\left(1-Q_{i k}(t)\right) d Q_{i j}(t)$

The obtained matrix of transition probabilities stationary value has the following form:

$$
p=\left\|\begin{array}{cccccc}
0 & p_{12} & 0 & p_{14} & 0 & 0 \\
0 & 0 & p_{23} & p_{24} & 0 & 0 \\
p_{31} & 0 & 0 & p_{34} & 0 & 0 \\
0 & 0 & 0 & 0 & p_{45} & 0 \\
0 & 0 & 0 & 0 & 0 & p_{56} \\
p_{61} & 0 & 0 & 0 & 0 & 0
\end{array}\right\|
$$

Probability Eq. (2) is a probability of a complex event: $p_{i j}$ of a transition to status $j$ and $F_{i j}(t)$ of a presence in $i$-status during time $t$, i.e. $p_{i j}(t)=p_{i j} F_{i j}(t)$ from which it is possible to define a conditional function of transition waiting time distribution

$$
F_{i j}(t)=\frac{p_{i j}(t)}{p_{i j}}
$$

As a result the following matrix is obtained:

$$
F(t)=\left\|\begin{array}{|cccccc}
0 & F_{12}(t) & 0 & F_{14}(t) & 0 & 0 \\
0 & 0 & F_{23}(t) & F_{24}(t) & 0 & 0 \\
F_{31}(t) & 0 & 0 & F_{34}(t) & 0 & 0 \\
0 & 0 & 0 & 0 & F_{45}(t) & 0 \\
0 & 0 & 0 & 0 & 0 & F_{56}(t) \\
F_{61}(t) & 0 & 0 & 0 & 0 & 0
\end{array}\right\|
$$

Which means that the initial matrix of independent functions of transitions waiting time distribution $Q(t)$ is transformed into two matrixes: transition matrix $p=\left\|d Q_{i j}(t)\right\| i, j=1, \ldots, k$ and matrix of conditional functions of transition waiting time distribution $F(t)=\left\|F_{i j}(t)\right\|, \quad i, j=1, \ldots, k$ defining functioning of semi-Markov model of sub-system element.

If all $F_{i j}(t)=0$, when $t<1$ and $F_{i j}(t)=1$ when $t>1$ (leaps happen in each unit of time), then semi-Markovian model transforms into Markov chain with discrete time. If $F_{i j}(t)$ are exponential, then semi-Markov model transforms into Markov model with continuous time.

Let us define the probability rate of the element functioning during the transition period as probability $P_{i j}(t)$ of the fact, that in the moment of time $t$ the element had $j$-status and in the moment $t=0$ it had $i$-status. The element that has left $i$-status may receive $j$-status in the moment of time $\mathrm{t}$ in different ways. First of all, if $i=j$ than it 
may not leave the status during the period of time or after leaving $i$-status it anyway returns to $i$-status by the moment of time $t$. Secondly, the element may receive a random $j$-status, occupying some intermediate status $n$ in the moment of time $\tau$. Probabilities of these two mutually excluding possibilities should be summarized. Therefore, we obtain an equation for probability $P_{i j}(t):$

$P_{i j}(t)=V_{i}(t)+\sum_{n=1}^{k} p_{i n} \int_{0}^{t} P_{n j}(1-\tau) d F_{i n}(\tau)$

After differentiation the integrand will have the following expression:

$$
P_{i j}(t)=V_{i}(t)+\sum_{n=1}^{k} p_{i n} \int_{0}^{t} f_{i n}(\tau) P_{n j}(t-\tau) d \tau
$$

Where $f_{\text {in }}(\tau)$ is a function of probability density of element residence time in $i$-status in the line $n$.

The first member in Eq. (9) $V_{i}(t)$ is a probability that the element will not leave $i$-status in the moment of time $t$

$V_{i}(t)=\left(1-F_{i}(t)\right) \delta_{i j}$,

where $\delta_{i j}=\left\{\begin{array}{l}1, \text { when } i=j, \\ 0, \text { when } i \neq j,\end{array}\right.$ is the Kronecker delta,

$F_{i}(t)$ is an unconditioned function of residence time distribution of semi-Markov model in $i$-status, it can be obtained directly via $Q_{i j}$ by formula

$F_{i}(t)=1-\prod_{j}\left(1-Q_{i j}(t)\right)$

In this case expression Eq.(10) will have the following form

$V_{i}(t)=\delta_{i j} \prod_{j}\left(1-Q_{i j}(t)\right)$,

where $\prod_{j}\left(1-Q_{i j}(t)\right)$ is a probability that semi-Markovian model will not transfer from $i$-status to any $j$-status during time $t$,

$1-\delta_{i j} \prod_{j}\left(1-Q_{i j}(t)\right)$ is a probability of transition to at least one $j$ status during time $t$.

The second member of expression Eq. (9) is a probability of consequential events where the system element conducts transition from status $i$ into status $n$ by the moment $\tau$ and then transfers from status $n$ into status $j$ during the remaining time $(t-\tau)$. Probabilities of frequent transitions are summarized by all intermediate statuses $n$, transition into which is possible from the initial status $i$ and integrated by possible transition time $\tau$ between 0 and $t$.

The system of linear integral equations Eq. (9) is the basic system. It allows obtaining expressions for status probabilities of the process under study.

\section{Methods of solution}

The traditional approach to solving such systems lays in implementation of Laplace transforms. However, the precise explicit solution here is only possible in the simplest situation, i.e. number of statuses is not more than three. Difficulties appearing during the study of real systems containing bigger number of statuses associated not only with rapidly growing number of calculations, but mainly with the fact, that obtained Laplace function images describing the transition process turn to be so complicated that it is not possible to find original functions.

To find the approximate solution, it is reasonable to implement iteration methods, having formulated the task as an optimization problem.

Beside the probability parameters semi-Markov model allows defining time parameters: unconditioned mathematical waiting time of element residence in each status and conditional mathematical waiting time of element residence in each status.

Unconditioned mathematical waiting time of element residence in i-status before the transition to any other status is defined by the expression:

$t_{i}=\int_{0}^{\infty}\left[1-F_{i}(t)\right] d t=\int_{0}^{\infty} \prod_{j}\left[1-Q_{i j}(t)\right] d t$

Conditional mathematical waiting time of element residence in status $i$ with the condition that the process transfers from status $i$ into status $j$ is defined by the relation

$t_{i j}=\int_{0}^{t}\left(1-F_{i j}(t)\right) d t$

\section{Conclusion}

Thus, the presented semi-Markov model of element functioning can be used for its probabilistic and temporal analysis. It is important to emphasize the problem of statistic data shortage, on the base of which one could define probabilistic characteristics of semi-Markov model used in control over the system supporting the set functioning. At the same time, the known instrument of the procedure of fuzzy set and fuzzy logic theory by Mischenko in [11], as it seems, could allow complex use of incomplete statistical data and expert information for defining possibility of attended system transition from one status to another described by Kruglov and Dli in [12].

\section{References}

[1] Anohin PK (1998), Selected works. Cybernetics of functional systems, Moscow, Medicine, pp: 292-293

[2] Anohin PK (1973), Principles of functions system organization, Moscow, Medicine, pp: 274-301.

[3] Sudakov KV \& Umriukhin EA (2001), New approaches to management activity optimization (human psychical abilities in P.K.Anokhin theory), International Journal of Management Theory and Applications, issue 2, available online: http://vasilievaa.narod.ru/contents-15.htm, last visit:03.01.2018

[4] Boyarinov YuG \& Mischenko VI (2009), Semi-markov models of industrial and economic systems, Software products and systems. Publishing house: ZAO NII Tsentrprogrammsistem (Tver) issue 2, pp: 124-127.

[5] Mhitaryan VS, Shishov VF, Kozlov AYu (2012), Probability theory and mathematical statistics: textbook for students of higher professional education institutions, Moscow: Publishing center Academy, pp: 245-251.

[6] Gertsbakh I (2000), Reliability theory. With application to preventive maintenance. Springer-Verlag. Berlin Heidelberg. New York, pp: 116-120.

[7] Howard RA (1960), Dynamics programming and Markov Processes. John Wiley \& Sons, Ins., New York London, 57-64.

[8] Suprun VN, Vakal AA (2009), Implementation of semi-Markov process for generalization of one model of artillery complex combat functioning. International scientific-technical journal "Artillery and small arms" No. 3 Kiev: CB "Artillery armament", pp: 9-11.

[9] Kozlov AYu \& Stroikov RA (2009), Information support of decision-making in technical-organizational system management. Modern information technologies. Issue 10 Penza PGTA, pp:4549.

[10] Shubenin AA \& Kozlov AYu (2009), Neuronet implementation of information support system of decision-making, Modern information technologies. Issue 10 Penza, PGTA, pp:143-149.

[11] Mischenko VI (2002), Analysis of approaches to modeling process of complex technical systems exploitation, Vest. Academy of military sciences. No. 3-4, pp: 72-77.

[12] Kruglov VV \& Dli MI (2002), Intellectual information systems. computer support of fuzzy logic and fuzzy conclusion systems, Moscow: Physmatlit, pp: 163-179. 